\title{
Identity, Collaboration and Radical Innovation: The Role of Dual Organisation Identification
}

\author{
By \\ Lisa O'Malley* \\ Department of Management and Marketing \\ Kemmy Business School \\ University of Limerick \\ E-mail: lisa.omalley@ul.ie \\ Michele O'Dwyer \\ Department of Management and Marketing \\ Kemmy Business School \\ University of Limerick \\ E-mail: michele.odwyer@ul.ie \\ Regina C. McNally \\ Department of Management and Marketing \\ Kemmy Business School \\ University of Limerick \\ E-mail: regina.mcnally@ul.ie \\ Stephen Murphy \\ Department of Management and Marketing \\ Kemmy Business School \\ University of Limerick \\ E-mail: stephen.murphy@ul.ie
}

${ }^{*}$ Corresponding Author

March 2014 


\section{Identity, Collaboration and Radical Innovation: The Role of Dual Organization Identification}

\section{Abstract}

This paper explores the nature of the relationship between identity and the radical innovation process in the case of the Solid State Pharmaceutical Cluster (SSPC). Antecedents and consequences of identification with the SSPC and the transitioning of identify from an organizational orientation to a dual organisation identity are discussed. We demonstrate that organizational identity can represent a substantial barrier to collaborating for radical innovation, and explicate how identity shifts can smooth the transition from competitor to collaborator. This study illustrates that opportunities were created through leveraging affinity to provide an environment conducive to radical innovation where members could interact, explore and collaborate.

Keywords: Identity, Collaboration, Innovation Network, Dual Organization Identification

\section{Research Highlights:}

1. Identification with a parent organisation can represent a substantial barrier to collaboration for subsidiaries within regional networks.

2. Working together on a specific common problem is fundamental to learning how to collaborate.

3. Dual organizational identification allows individuals to contribute to multiple agendas without any apparent conflict of interest.

4. Collaboration should not be overprescribed at the outset as this limits the possibilities for RI. 


\section{Identity, Collaboration and Radical Innovation: The Role of Dual Organization Identification}

\section{Introduction}

A radical innovation $(\mathrm{RI})$ requires substantially different technology and marketing skills compared with existing offerings within an industry (Chandy and Tellis 1998). As is evident in this concept, the term 'radical innovation' typically relates to new products, although it also applies to new services and new processes. A key construct in facilitating efficient and effective innovation processes is that of innovation networks (Powell, Koput and Smith-Doerr 1996). Localised networks have sprung up around the world - e.g. Silicon Valley, Ireland, and Taiwan (Bresnahan, Gambendella and Saxenian, 2001) and can include R\&D organisations, universities, and research laboratories (Lee, Lee, and Pennings, 2001). Such localised networks are regarded as an important antecedent to radical innovation (Gordon and McCann, 2000), and have been encouraged and supported by governments in many countries. Central to the development of regional networks is the belief that geographical proximity and cultural sensitivity result in more effective knowledge transfer than that experienced between multi-national companies (MNCs) and their overseas subsidiaries (Birkinshaw and Hood, 1998). This may be particularly the case for collaborations involving established firms with clearly developed identities and affiliations. However, not all inter-organizational collaborations result in innovation (Faems, Van Looy and Debackere, 2005), with many failing to generate any collective action at all (Lawrence, Hardy and Phillips, 2002). Thus, the question that drives our research is why do some multiorganisation collaborations work well while many fail?

Radical innovations are generally juxtaposed with incremental innovations, which are modifications to existing products (Chandy and Tellis 1998). This juxtaposition of terms suggests that 'innovativeness' varies from minimal change to dramatic change. Furthermore, innovativeness is multi- 
dimensional: newness can be examined from the perspective of the customer and from the perspective of the firm in terms of technology and/or the market (McNally, Cavusgil, and Calantone 2010). Newness is one of the many planned and unplanned, permanent and transient, attributes and features that shape stakeholder perceptions of the organisation (Markwick and Fill, 1995; Gioia et al. 2000), thereby forming the basis of its identity. Identity is "the articulation of what the organisation is, what it does and how it does it, and is linked to the way an organisation goes about its business and the strategies it adopts" (Markwick and Fill, 1995: 397). An articulate and authentic identity increases organizational visibility while providing competitive advantage and helping to communicate corporate strategy (van Riel and Balmer, 1997). Thus, identity is critical in organizational sustainability (Gioia et al. 2000).

We examine a multi-organisation collaboration in the Irish pharmaceutical industry that is regarded as highly successful based both on members views and funding achieved. Our research finds that members of the individual organisations transitioned from identification solely with their organisation to dual organisation identification, where members of the inter-organizational collaboration simultaneously developed a sense of identification with two different organizational entities (Vora and Kostova 2007). Within the Irish Pharmaceutical industry, these two separate identities (own organisation and SSPC) work in a symbiotic manner, supporting and improving each other through two-way, symmetrical, and simultaneous feedback that allows the collaboration to operate effectively. As such, we demonstrate how identification with one's parent organisation can represent a substantial barrier to collaboration within regional networks. However, collaboration is legitimised and embedded within on-going $\mathrm{Rl}$ activities where members exhibit dual organizational identification.

This paper is structured as follows. First, we explore literature on radical innovation, identity, organizational identification and dual organisation identification. Next, we characterize the Irish pharmaceutical industry as the context in which a successful collaboration across multiple firms and universities took place, and explain the research method employed in this 
study. The findings are discussed in terms of the barriers to collaboration, the transitioning of identity from a single organizational orientation to a dual organizational identity, and the consequences of this for the studied collaboration. Finally, we extrapolate insights from these findings and provide directions for further research into understanding the dynamics of identity and collaboration in the context of radical innovation as well as highlighting recommendations for managers and policy makers on supporting regional networks.

\section{Radical Innovation}

Antecedents of, and processes supporting, incremental innovation have been well documented and receive considerable empirical support, while the antecedents and processes related to radical innovation (RI) are not well documented (McDermott and O'Connor 2002). This may be due to the higher degree of informality, intense communication and cooperation among actors, a lack of decision-making rules, and the emphasis on creativity and risk-taking required for radical innovation relative to incremental innovation (Gatignon et al., 2002; Song and Swink, 2002). In terms of the process, radical innovation develops through phases of exploration, design and applications, and dissemination (Lundgren, 1995; Möller, 2010; Anderson and Tushman, 1990), and produces fundamental changes in the activities of an organisation and large departures from existing practices (Ettlie and Subramaniam, 2004). Because few firms have the necessary resources for RI internally, collaboration between firms has been viewed as an important driver of innovation (Chesbrough 2003; Story, O'Malley and Hart, 2011), so much so, that it is promoted and encouraged by governments worldwide (Etzkowitz and Leydesdorff 2000; Mowery and Rosenberg 1993).

Adding to previous conceptualisations of $\mathrm{Rl}$, we argue that some collaborative efforts should themselves be considered a radical innovation because they represent a radical departure from how firms historically interact with each other. In this paper, we consider the case of the Solid State Pharmaceutical 
Cluster (SSPC) in Ireland to highlight (i) the barriers to collaboration as perceived by its original members, (ii) the identity change which facilitated success, and (iii) the consequences of collaboration including significant changes to these firms' business models. Moreover, while the collaboration is itself a radical innovation, importantly, it has paved the way for more material innovations in product and process.

\section{Identity}

"To understand identification, one must first understand identity" (Ashforth, Harrison, and Corley 2008, p. 327). Identity has been examined from the perspectives of social identity theory and identity theory. Social identity theory, developed by Tajfel (1978) and Tajfel and Turner (1986), separates social identities from personal identities. Whereas personal identities are individuals' idiosyncratic bundle of attributes, such as traits, abilities, and interests, social identities relate to group memberships, are shared by group members, and distinguish 'ingroup' members from 'outgroup' members (Tajfel 1978, Tajfel and Turner 1986). Identity theory relates to the meanings individuals associate with roles, such as occupations, careers, and relational networks (Stryker and Burke 2000). Roles are embedded in valued relational networks; the likelihood of roles being 'enacted' (i.e. activated and performed) increases with the value the individual places on the relationships (Burke and Reitzes 1991). Within organisations the core of identity consists of cognitions related to group membership (Tajfel 1978), which include values, goals, beliefs, stereotypic traits, and knowledge, skills, and abilities (Ashforth, Harrison, and Corley 2008). We argue that while the core aspects of identity are always exhibited, the broader content operates more independently and individuals vary in the extent to which they embody organizational identities.

\section{Organizational Identification}

Organizational identification occurs when an individual's beliefs about his or her organisation are recognised or adopted as their own. Ashforth and Mael (1989) suggest that identification relates to aggregates of people, where aggregation occurs at various levels of groupings, including organisations, business units, departments, work groups or teams (Ashforth, Harrison, and 
Corley 2008). 'Lower-order' identities, or smaller and more proximal groupings such as those an individual works with most frequently and intensely, generally evoke stronger identifications. Organizational identities generate strong identification when the organizational identity is of very high status, it is under perpetual threat, it is unique, the identity is strongly and widely held across subunits, if decision-making is highly centralized, and when individuals are owners, senior executives, or boundary spanners (Ashforth, Harrison, and Corley 2008).

Organizational identification is an iterative, developmental process involving interaction between individuals and organisations (Ashforth, Harrison, and Corley 2008, Pratt 1998). From the perspective of individuals, the identification process involves enactment, sensemaking, and identity narrative construction (Ashforth, Harrison, and Corley 2008). Enactment occurs when individuals 'try on' an identity (i.e. individuals attempt to behave as they expect someone with that identity to behave). The next step of sensemaking involves observing responses to their behaviour and interpreting the meaning of such responses. In the final step, they update their personal story of who they are and who they are likely to become.

Within organisations, individual identification is supported and managed through a process involving sensebreaking and sensegiving (Ashforth, Harrison, and Corley 2008). Sensebreaking 'involves a fundamental questioning of who one is when one's sense of self is challenged ... [creating] a meaning void that must be filled' (Pratt 2000, p. 464). Thus, sensebreaking accentuates knowledge gaps to motivate further identity exploration, creating tension and resulting in a search for meaning. This tension and search for meaning enhances the opportunity for sensegiving, which refers to attempts to guide the 'meaning construction of others toward a preferred redefinition of organisation reality' (Gioia and Chittipeddi 1991, p. 42).

Pratt (1998) suggests there are two alternative processes of identification: emulation and affinity. The iterative, back-and-forth process explained above captures the 'identification through emulation' process (Ashforth, Harrison, 
and Corley 2008), where identification occurs when individuals incorporate organisation beliefs and values into their own identities (Pratt 1998). In identification through affinity, "like meets like" (Pratt 1998, p. 174); here, individuals use their own identity to assess if an organisation has values and beliefs similar to their own.

\section{Dual Organizational Identification}

Dual organizational identification (DOI) is an individual's sense of identification with two organizational entities (Vora and Kostova 2007). Multiple identities can be salient simultaneously when identities overlap, are relevant to a specific context, are cognitively linked to each other, and when individuals can tolerate such simultaneous identifications (Ashforth and Johnson 2001). Research on multiple identifications is scant (Vora and Kostova 2007), and examines the multiple identifications separately, without considering how they might work together (Gregersen and Black 1992). However, Vora and Kostova (2007) develop a conceptual framework regarding how subsidiary managers in multinational enterprises (MNEs) simultaneously manage their identifications with both the subsidiary and the enterprise.

DOI is complex, consisting of two separate and independent characteristics: relative magnitude (the relative strength of the sense of identification with each of the two entities) and form (the perceived configuration of the two identifications in terms of overlap) (Vora and Kostova 2007). Magnitude is not driven by proximity; rather, it is driven by the abilities of each entity to fulfil the individual's self-enhancement and uncertainty reduction needs. With this definition of magnitude, it is possible for those in the local subsidiary to identify more strongly with the MNE than with the local subsidiary.

In this research, we examine how the identifications of managers in a multiorganisation collaboration in the Irish pharmaceutical industry evolved from identification solely with their MNC to dual organisation identification. In particular, we explore how 'identification through affinity' enabled changes in behaviour that supported RI. 


\section{Ireland, Industrial Policy, and the Pharmaceutical Industry}

The context of this collaboration involving five Irish universities and nine pharmaceutical companies (entitled the Solid State Pharmaceutical Cluster) is particularly interesting because the pharmaceutical industry in Ireland is highly regulated and insular (Van Egeraat, 2006; Hannon et al., 2011), with firms closely guarding intellectual property (Henderson, Orsenigo and Pisano, 1999). These firms have historically maintained their distance and have no history of collaborating with academia (Van Egeraat, 2006; Hannon et al., 2011), or with each other.

Historically the Industrial Development Authority (IDA) promoted Ireland as a low-cost manufacturing base. This strategy attracted eight of the top ten leading international pharmaceutical companies to establish Irish subsidiaries. The highly educated, English speaking workforce and attractive corporate tax regime further enhanced Ireland's competitive advantage. However, by the early 1990s the Irish economy began to experience such dramatic growth that the Irish pharmaceutical subsidiaries became vulnerable to competition from subsidiaries in lower cost economies across the world, a situation mirrored in other Irish manufacturing-based industries. In order to overcome this challenge, the Irish Government through the IDA attempted to shift the economy away from reliance on manufacturing and towards the creation of discovery laboratories. However, Ireland lacked the necessary infrastructure for excellence in science and technology, and collaboration with academia was very limited (ICCSTI, 1999 cited in van Egeraat, 2006). Recognising the need for collaboration between firms and supported by academia, government policy through Science Foundation Ireland (SFI) set out to establish a number of centres of excellence in order to advance basic research (Orsenigo, Pammolli and Riccaboni, 2001), and create opportunities for innovation through "focused attention to common problems" (Department of Enterprise, Trade and Employment, 2008, p. 13). Less than a decade ago, collaboration was not on these firms' agendas, and government agencies were acutely 
aware of the barriers to fostering collaboration. This paper explores how these barriers were successfully overcome.

Central to this paper is a shift in identity by members of the firms involved in this collaboration from perceiving themselves primarily as multinational subsidiaries that were physically located in Ireland, to identifying more with local pharmaceutical firms and with the Irish agenda through the idea of 'Ireland Inc.' This shift in identity was greatly facilitated by the nature of global competition within multinational subsidiaries as well as specific changes to Ireland's competitive position within this space. By adopting the rhetoric surrounding the challenging times facing Ireland, key actors ensured that the pharmaceutical industry, and the SSPC in particular, were at the heart of any solution to Ireland becoming an international pharmaceutical hub. Although a localised case study, we identify important implications for the creation and development of innovation networks in different industries across different global locations. In particular, we employ the construct of dual organizational identification via the affinity process to explain the transition from identification solely with members' home organisation to simultaneous and strong identification with both the home organisation and to the new interorganisation collaboration, which enabled the collaboration to sustain itself.

\section{RESEARCH METHOD}

In order to understand the processes through which collaborative activities developed within this network, we interviewed the key individuals who initiated and developed the SSPC because it was "their perception, interpretation and actions" (Makkonen, Aarikka-Stenroos, and Olkkonen, 2012: 291) that created [and continues to maintain] this network. Informants were drawn from the five universities and nine firms involved in the initiation of the innovation collaboration. In total, 18 participants involved in the formation and early stages of the SSPC were available for interview. Initial interviews were conducted over a three month period in early 2012 and were supplemented by further interviews in January 2013. Interviews lasted between 50 and 90 
minutes. Please refer to Table I for a list of participants (Informant names have been changed to protect their anonymity). Because our focus is on the barriers to collaboration and how these were overcome, in this paper we rely on insights and experiences of the key actors who initiated the SSPC.

Adopting Wengraf's (2001) structured approach to narrative interviewing, we invited key actors to share their understanding of how the network was conceived and how collaboration emerged. In so doing we acknowledge that informants construct and communicate their experiences through the stories they tell (Bruner 1991), and that these stories provide legitimacy and accountability for their actions (Czarniawska, 1997). Thus, through narrative interviews we accessed "the same kind of data that organizational members use to plan, enact, interpret, and evaluate their own actions and those of others" (Pentland, 1999: 717). As a result, their understanding of the barriers to, and consequences of this collaboration, emerged organically in the stories they told.

Each interview began with a single question intended to induce narrative (SQUIN), in our case "tell me the story of the SSPC as you see it." In this way, informants offered a "purposeful account" (Jovchelovitch and Bauer, 2000) of how and why the SSPC was formed and the centrality of the participants' roles. Each story (or micro narratives, Boje, 2001) was related orally, from memory and, in line with the biographical narrative interpretive method (BNIM), started in different places and times and (occasionally) fore-grounded different events (Czarniaska, 1997). Informants were in control of their own story (Wengraf, 2001). As interviewers, we focused on listening actively and on taking notes. Informants responded very differently to this opening question with several talking for 20 minutes or more and others struggling to speak for 2 minutes. The next phase of the interview followed in a similar manner but this time we introduced topic questions aimed at inducing 
narrative (TQUINs). These questions became more specific, i.e. asking for more detail about topics raised by the participant during the first phase of the interview. The third phase of the interview allowed us to ask questions based on our preliminary analysis of the first two phases, as well as theoretical and practical questions arising from our emerging understanding of the collaboration and from other interviews.

Each interview was transcribed and appended to notes taken at the time of the interview. The first reading of interview accounts was intended to appreciate the micro narratives (i.e., the story within the story) (Boje, 2001), recognise plots and protagonists as identified by informants, and identify key individuals to target for further interviews. Informed by the wider literature on innovation networks, knowledge sharing and collaboration, we undertook a thematic analysis within, and across, interview transcripts. However, as we read and re-read the transcripts we began to appreciate that language, metaphor and identity impacted on the creation of this network, and we actively sought out theoretical frames that further informed our analysis and supported our sense-making processes. We interrogated and supplemented our interpretations through reviewing published government reports, the SSPC website and related materials. We shared our analysis of the data with key actors to ensure they were not being misrepresented.

\section{Findings}

\section{Overcoming Barriers to Collaboration:}

Historically, the atmosphere between multinational subsidiaries was distant and fearful, an outcome of the degree to which pharmaceutical companies worldwide protect their intellectual property (Henderson, Orsenigo and Pisano, 1999). As a result, subsidiary firms maintained distance from other pharmaceutical subsidiaries within the same geographical region.

I would say that ten years ago you were afraid to be talking to someone from another competitor company. I suppose there was 
that level of fear. I don't know where that originated, [but] there was real fear. [Peter, Pharmaceutical Company 2]

The parent company decided which of its subsidiaries across the world manufactured which product. Philip describes below how this usually worked.

Drug discovery would tend to come from head office. They would develop it to a certain stage and then they would go into clinical trials. And then towards the end of clinical trials they would start to think how are they going to manufacture it. And they would typically choose a plant, one of their plants around the world. It's at that stage the Irish companies would get involved. And they are competing to be the plant that gets the drug. And then they will manufacture it for some years. [Philip, University 1]

The high end activities of drug discovery are primarily located at the parent headquarters and manufacturing of the drug takes place around the world. As a result, competition is intense between subsidiaries and manufacturing cost becomes a significant choice criterion. Thus, the dynamics of internal competition between subsidiaries is a critical determinant of which subsidiaries survive (Almor and Hirsch, 1995), and is largely driven by the track record of those subsidiaries (Birkinshaw and Hood, 1998) and the cost climate in which they operate.

One important downside of the growth in the Irish economy around the turn of the millennium was that Ireland was becoming less competitive in terms of costs, and, as such, their competitive advantage vis a vis sister subsidiaries around the world was being eroded:

We knew that our old manufacturing mandate was not going to serve us in the future because of the impact of the Celtic Tiger raising our costs significantly. Therefore, we were being challenged on a competitive scale by other locations. [William, Pharmaceutical Company 1]

This competition between other MNC subsidiaries became a significant threat to the Irish Pharmaceutical industry, and this, perhaps more than anything else, initiated the process of sensebreaking (Ashforth, Harrison and Corley 2008) with Irish firms increasingly regarding their sister subsidiaries as their competitors. 
As you may know, the pharma sector is under threat from India and China because they can produce materials much cheaper. [Donald, University 1]

In response to this acknowledged threat, industry participants created a special interest group, which was central to breaking down the perceived barriers between firms.

Having a group like IBEC ${ }^{1}$ PharmaChem Ireland, that's got people to get to know each other a bit better and relax a bit to share our challenges. In parallel the world was changing and our challenges were becoming more and more similar. Losing manufacturing was a problem that we all had. Then we were able to rally around this problem of how do we stop hemorrhaging manufacturing out of Ireland? [Peter, Pharmaceutical Company 2]

The threat to the pharmaceutical sector was perceived as very real - with the various firms experiencing the same challenge of being less competitive than their sister subsidiaries in other locations. This was problematic as a number of patents were due to expire for blockbuster drugs manufactured in Ireland. Therefore, in order to maintain exports and jobs, these companies needed to ensure they could successfully compete to manufacture new drugs. Although Irish firms were aware that they were also experiencing similar problems vis a vis their parent organisations and sister subsidiaries, they continued to identify with their parent organisations and maintained their distance from other Irish firms. The shift from 'real fear' of being seen talking to other firms seems to have been overcome by the obligation to save jobs in each of their organisations.

For some of the companies, they view [collaboration] as much of a strategic benefit to Ireland as it was to their own individual companies.... I think the nature of the companies in Ireland [is that] for them, their competitors may be sister sites in other countries... [Kevin, University 3].

Thus, because the challenges faced by individual firms became more similar, Irish firms began to identify more with each other and there was a perceptible

\footnotetext{
${ }^{1}$ Pharmachem Ireland is a subsidiary of the Irish Business Employers Confederation (IBEC) that focuses on the pharmaceutical and chemical industries in Ireland.
} 
shift in identity from 'we' [individual firm] to 'we' denoting pharmaceutical companies in Ireland. This shift occurred because of the increasing cost base challenging all firms based in Ireland (we), along with increased competition from sister subsidiaries, particularly China and India (them). The shift to 'we' denoting pharma Ireland was also facilitated through identification with, and participation in the local Business confederation (IBEC) as a specific industry grouping. Following several meetings and discussions, this group produced a Strategic Plan for the industry in Ireland. In this they linked the fate of the Irish pharmaceutical industry to the fate of the Irish economy, delineating that a sector contributing $56 \%$ of Irish Exports, accounting for more than $€ 40$ billion annually, could not be allowed to fail:

Ireland depends heavily on the pharmaceutical sector which generated over $50 \%$ of Irish exports, worth some $€ 44$ billion, in 2008. Responding to the challenges facing the sector must be a national priority. In order to remain the great success story that Ireland has become, industry, government and other related stakeholders need to meet these challenges head on. Companies need to respond by linking research directly to manufacturing, via process and product development. (Innovation and Excellence PharmaChemical Ireland Strategic Plan).

When SFI announced a call for applications for the development of Strategic Research Clusters, Philip invited industry to come on board.

So we approached the industry then and we just profiled the kind of capacities which we had. They were very interested in the presentation that we made. There was some big names there who were opinion leaders.... they were all quite supportive of the whole idea. They said this expertise is something that we definitely lack in Ireland. [Philip, University 1].

This response marked a further transition in the identity of the individual pharmaceutical companies who were beginning to align more with the challenges facing other Irish pharmaceutical companies, than they were with their parent organisation. This was essential in overcoming their historically competitive stance - a significant barrier to collaboration. While Philip anticipated that only two or three firms would get involved in the initial programme, articulation of the capacities and expertise held by the academics proved far more attractive than expected. 
[Philip] was actually surprised with how receptive we were to his proposal... He went around the companies and I think of all the companies only one turned him down and he ended up with 9 companies that would be prepared to work together with the institutions. [Peter, Pharmaceutical Company 2]

\section{Collaborative Consequences: After the Introduction of the SSPC}

The SSPC was established in 2007 as one of three Strategic Research Clusters, and secured funding of $€ 6.97$ million from SFI. Its focus was to support knowledge networks to create distinctive competences that would ensure that Ireland remained competitive in the global pharmaceutical industry (Hannon et al., 2011). The SSPC was formed ostensibly to conduct research in the area of crystallization of pharmaceutical solids and has since developed and utilized important RI competences. Since its inception, members of the SSPC have engaged in a number of successful research collaborations, have developed the Best Practice Crystallisation Website and initiated collaborations outside of the crystallisation space. Indeed, such has been their success that within 5 years additional funding of $€ 40$ million had been secured in order to establish The Synthesis and Solid State Pharmaceutical Centre - involving 17 pharmaceutical companies working with 90 researchers across 8 academic institutions. Before the SSPC was formalised, Irish firms (like their global counterparts) maintained arm's length relationships with competitor subsidiaries (Henderson, Orsenigo and Pisano, 1999).

In September 2008 the academic partners rolled out training modules for collaborating partners, in various locations, on topics relating to crystallisation to build a common identity. High level training was provided which focused on demonstrating the underlying research behind the processes in which they were actively involved. This served to overcome participants' reticence to share information, embedded a culture of collaboration and established opportunities to develop and demonstrate competences for further radical innovation activity. In addition the SSPC 
embarked upon an ambitious venture to create a 'best practice crystallization port'.

We decided to create a best practice crystallization port... So we looked at the manufacturing process of an active ingredient and we divided it into logical blocks and see if we can put teams together that will study the state of the art in terms of literature and what is happening in companies and write a best practice approach for crystallization of the pharmaceutical compound. So we said let's put some academics, students and industry people from different companies into 8 groups and put them working together. We ended up with about 64 people working on this and I think the fact that we did this and we had the training done kind of gelled the cluster early on. It broke down a lot of barriers because all of these people were openly sharing information about how to do things. [Tom, University 1].

Within two years SSPC developed the Best Practice in Crystallization website (BPX) that launched on the 6th of November 2009. The formation of BPX.ie resulted from the combined efforts of academic and industrial members of the SSPC, working together to define the current state of the art in pharmaceutical crystallization. As such the BPX website is recognized within the network as a testament to the success achieved through collaboration. A major part of the process was capturing tacit knowledge and sharing it through this purpose built website, which had a profound impact on the learning community and its identity. As a result, it exceeded the expectations of those who initiated the collaboration:

Companies came together and had a look at it and found that they were actually getting more value than they expected. They thought that it would just be the getting to know you bit at the beginning. But companies actually started to really buy into it. It was the first time they thought it was a relationship and they were learning. They found that they were learning as much from their peers as they were from the academics. [Donald, University 1].

Initially framed as Ireland Inc. against the 'sister companies' in the global marketplace, one participant identifies how this has in some sense come full circle with the parent companies now benefiting too:

I was in New York two weeks ago and I did a presentation to all of the R\&D, about 120 people from [Pharmaceutical Company 2] and all of the manufacturing people, and basically I put up the website and very simply said to them if you're planning on doing crystallization next Monday morning - don't - Log onto this website first. I sent a very clear message to all of the people there and I'm 
sure Tom had a lot more people looking for entry and I'm sure he must have about 200 people from [Pharmaceutical Company 2] looking for entry. Their reaction is "Oh my God, you're sharing stuff with [other Pharmaceutical]?", followed by "Can we get access to it?"... That's what the cluster is about, its taking that common knowledge and putting it into one place. It's very powerful. [Peter, Pharmaceutical Company 2]

Peter's narrative provides some relevant perspective and context on the level of radical innovation achievement that the SSPC has attained. Here, we see how the best practice website represents an on-going resource that is also valuable to parent organisations. This demonstrates that identification with other Irish firms did not undermine subsidiaries' identification with their parent firms. Rather, through dual organizational identification (Vora and Kostova, 2007), the benefits of collaboration became available to all. While Peter's colleagues at Pharmaceutical Company 2 were initially shocked at the fact that this information was being shared with others (competitors), their next reaction was to look for access. Therefore, value is ultimately created for the Irish firm as they gain a specific area of expertise, which aids them in competing against sister firms within their own corporate structure.

When they have a success like the one I described they will go and communicate their successes to head office, and their kudos is growing.... The bigger the company the more they tend to communicate with head office. They just want them to know what's going on. Sometimes there is a kind of perverse delight in saying corporate couldn't solve this problem but we did. [Philip, University 1]

Thus, Irish firms grew in confidence and were able to clearly demonstrate valuable innovation activity and outcomes to their parent organisations. When seeking approval from host organizations for ongoing collaborative activities, they spoke in terms of return on investment and the potential to add value, and this was fundamentally to ensuring senior management commitment to their participation in the SSPC. Moreover, as the collaboration evolved, through a process of engagement and interaction the 'program for action' evolved and became more relevant not only to the problems they currently faced, but also to problems they anticipated in the future:

The whole thing emerged. The whole thing has changed in the five years. We had lots of discussions around that time and you wouldn't have been able to predict 5 years ago where we are now. Because we 
started off with a programme for SFI .... [but] at the mid-term review three years later, it was all completely different. The interaction with the different colleagues, particularly industry colleagues, was hugely influential. They kind of know what's coming down the line, you know. They know the technology that they are not using today but that they expect to be using in two years' time. And that's what they want from the cluster. [Philip, University 1]

\section{DISCUSSION}

The SSPC is presented here as a successful innovative collaboration among ostensibly competing firms to further their ability to succeed in a highly competitive global marketplace. In terms of understanding how this innovation collaboration works so effectively, we demonstrate the key role of affinity in transitioning members from organizational identification to dual organizational identification. The common ground for the different stakeholders involved in the SSPC (i.e., educational institutions, pharmaceutical companies) was a desire to see Ireland develop as an international pharmaceutical hub. Achieving this did not require any alteration of individual values or beliefs (i.e., the organizational identity could remain the same), but based on recognition of shared core common values and beliefs, affinity with a new identity was not only possible, but also supported a rapid shift to dual organisation identification.

The members to whom we spoke articulated the importance of the SSPC and their identification with it. This contrasted significantly from their original identity as subsidiaries of a multinational parent organisation competing with other pharmaceutical firms in Ireland. The shift in identification allowed them first to view sister subsidiaries as their competitors for manufacturing business, and second, to view other Irish firms as potential collaborators. It was this that allowed them to benefit from the geographical proximity and cultural sensitivity that is central to successful regional innovation activities (Birkinshaw and Hood, 1998). This transition enabled members to engage in the kinds of effective collaboration essential to the discovery stage of RI (see Story, O'Malley and Hart, 2011). 
Having recognised the value of securing the future of the Irish Pharmaceutical Industry by securing a strategic research cluster, the original members of the SSPC established a basis for collective engagement by successfully defending the SSPC proposal to the expert panel.

I think a lot of the way that the companies here are looking at this is that they have to fight their corner in some respects for the Irish facility against their sister companies in other countries. So if they can show capability in Ireland, that does all of the companies that are based here good. It means that there is a strength developed within the country. [Donald, University 1]

In explaining the new mindset, Donald illustrates the gravity of the challenges faced by the Irish pharmaceutical sector. By individually aligning with the "Irish facility" of the company, there seems to be a perceptible shift toward country over company, as evidenced by other narratives.

Obviously people's first responsibility is to their companies but there is a kind of commitment to Ireland Inc., as they say, you know. People are proud of the success of the industry in this country and people are generally very happy to see the success of other companies here. On a local level, the cooperation is much stronger than competition... [Geoff, Pharmaceutical Company 3]

By creating this meaningful Irish subsidiary identity, local management was empowered to "take certain actions for the benefit of their country and for themselves" (Birkinshaw and Hood, 1998, p. 774). In terms of the latter, this shift in identity enabled collaboration that could fundamentally change the competitive landscape (Leifer et al., 2000).

The way in which firms are structured in a global economy results in a more tangible competition between subsidiaries in other countries, rather than with competitors in Ireland. Firms are beginning to recognise the advantages that can be gained through pooling resources and expertise and this is reflected in a more open attitude towards collaboration and shared identity. Importantly, this rationale enabled group members to "construct themselves, the problem, and the solution as part of a collaborative framework in which the potential for joint action is both significant and beneficial" (Hardy, Lawrence and Grant, 2005, p. 63). 
Addressing the problems facing the pharmaceutical industry became an Irish problem, involving not only industry participants but also government and academia. This served to identify government and academia as important stakeholders with significant resources to be called upon. Equally, by articulating the SSPC proposal as a collaboration between industry and academia, they aligned with government policy to create strategic research clusters and with Ireland's ambition to become a 'knowledge economy'. While this highlights the utility of government policy to support radical innovation activities through collaboration, it also demonstrates that the availability of public funding is a necessary but insufficient condition. Localised efforts to identify and overcome barriers to collaboration are fundamental to successful regional RI activities.

Irish firms needed to demonstrate their technical superiority over sister subsidiaries and this helped to form the basis of an alternative identity. The desire to be part of something bigger through the articulation of Ireland Inc provided the necessary glue. Thus, an emergent identity provided a basis by which participants could identify issues as being "relevant to their organisation and consequently identifying themselves as interested and affected by it" (Hardy, Lawrence and Grant, 2005, p. 64). This created the basis of a new collective identity that facilitated the initial collaboration.

The leaders within the SSPC recognized the importance of affinity to collaborative innovation activities and, on this basis; they successfully adjusted the use of terminology in relation to the exchange partners they were addressing. By focusing on the specific problem of crystallization a new identity emerged around SSPC and this inspired synergistic action. Thus, focusing on a specific common problem was fundamental to learning how to collaborate and to advancing their shared vision of Ireland as having a strong international pharmaceutical industry.

\section{CONCLUSION}

Given that collaboration between firms has become increasingly important for radical innovation (Story, O'Malley and Hart, 2011), localised innovation 
networks involving R\&D organisations, universities and research laboratories (Lee, Lee and Pennings, 2001) have been developed in various countries around the world (Bresnahan, Gambendella and Saxenian, 2001). Because such networks are localised, firms' geographical proximity and cultural sensitivity are argued to result in better knowledge transfer than is possible between MNCs and their overseas subsidiaries (Birkinshaw and Hood, 1996). However, the development of localised innovation networks is not always unproblematic and without significant barriers.

This case demonstrates that less than a decade ago, collaboration between Irish pharmaceutical firms was considered impossible because of the highly competitive atmosphere that existed (Van Egeraat 2006; Hannon et al., 2011). This, we argue, resulted from local subsidiaries identifying solely with their parent organisations. However, changes in the global economy together with dramatic increases in Ireland's cost-base resulted in Irish firms beginning to view their sister subsidiaries in other countries as their competitors (competing for opportunities to manufacture new drugs) thereby initiating a process of sensebreaking in terms of identification with parent firms. Moreover, because this was a challenge faced by all Irish subsidiaries vis a vis subsidiaries in other countries, they began to identify with other Irish subsidiaries and with the potential loss of pharmaceutical employment as an Irish problem. Importantly, involvement in IBEC created a platform for engagement and discussion and, ultimately, a readiness for collaboration. Thus, when one Irish university proposed establishing a formal collaboration between universities and the pharmaceutical industry the majority of firms came on board willingly, and began to identify with the SSPC. However, they did not eschew one identity (parent MNC) in this process; rather what emerged was dual organizational identification (Vora and Kostova, 2007). Thus, members of the Irish pharmaceutical industry were able to collaborate with each other and to benefit from the geographical proximity and cultural sensitivity that is central to successful regional innovation activities (Birkinshaw \& Hood, 1998). By overcoming barriers to communication, members of the SSPC were able to engage in the kinds of effective collaboration essential to the discovery stage of $\mathrm{Rl}$ 
(see Story, O'Malley and Hart, 2011). However, members did not eschew identification with their own organisations. Rather, they were able to share insight and knowledge with their parent organisations.

Collaboration is crucial to the development of radical innovations (Gordon and McCann 2000; Story, O'Malley and Hart 2011). Thus, if industry members can't or won't interact (as was previously the case for members of the Irish pharmaceutical industry), then collaboration does not occur. This paper demonstrated how firms in this study were able to engage in collaborative RI activities through the development of dual organizational identification. This allows them to contribute both to their own organizational agenda and to the SSPC without any apparent conflict of interest.

There are important insights for radical innovation theory development that can be extrapolated from this study. First, context specific narrative accounts provided in this study extend our understanding of the process through which fundamental changes in the business model (necessary for RI) are enacted (Ettlie and Subramaniam, 2004). Where the collaboration is a radical departure from traditional ways of operating, shifts in identity and identification may be necessary to overcome barriers to engagement. In the case of the SSPC, opportunities were created through leveraging affinity to provide an environment conducive to radical innovation where members could interact, explore and collaborate.

In considering these findings it should be noted that the research methodology adopted for this study was exploratory (as required for the theory building necessary for this study) and was limited to the key actors involved in establishing the SSPC. Future research should extend the qualitative research to include key stakeholders in the SSPC to explore a more holistic interpretation of dual organisation identity. In addition we propose that a quantitative study, with a wider group of stakeholders from within the network, be developed in order to suggest a model to map the transitioning from organizational identification to dual organisation identity, this 
could be replicated with successful innovation networks in other regions for comparison.

In terms of managerial implications, it is clear that creating a dual organizational identification enabled local firms to engage in collaboration within the pharmaceutical industry in Ireland and to also share emerging resources with their parent firms. Thus, opportunities must be created to ensure that learning can be shared, so that the parent organisation can see a benefit from their subsidiary collaborating within the local innovation network. It is also clear that the agenda for action must be fluid. It must be capable of responding to opportunities as they present themselves (funding bids, practical problems etc.), rather than articulating a priori how and when interaction will occur. If SSPC had followed a prescribed template from the outset, it would be far more limited in its intentions than it currently is, and would have celebrated far fewer successes. The creation and co-ownership of the website is testament to this, as is the invitation extended to parent and sister firms to avail of this resource. Thus, while this collaboration is in itself radical - importantly, it has led to further changes in how firms interact and identify with each other and with their parent organizations. In doing so, it also has enhanced the potential for all to engage in more $\mathrm{Rl}$ activities thank could have been possible prior to the formation of the SSPC. 


\section{NOTES}

1. IBEC is a business networking forum and within this there had been a pharmaceutical group in existence since 1994. Strategic issues were discussed but no formal collaboration had emerged until after the proposal for the SSPC cluster.

2. The academic contributors are University of Limerick, National University of Ireland, Galway, Trinity College Dublin, University College Dublin, and University College Cork. The Pharmaceutical Company members are Janssen, Schering Plough, GlaxoSmithKline, Merck Sharpe and Dohme, Roche, Pfizer, Eli Lilly, Clarochem, Hovione, and Bristol Myers Squibb.

3. SSPC website is http://www2.ul.ie/web/WWW/Faculties/Science \%26 Engineering/Research/ Research Institutes/MSSI/Research Themes/SSPC/Governance

\section{REFERENCES}

Almor, T. and Hirsh, S. (1995). 'Outsiders response to Europe 1992: Theoretical and empirical evidence'. International Journal of Business Studies, 26, 223-239.

Anderson, P. and Tushman, M.L. (1990) "Technological Discontinuities and Dominant Designs: A Cyclical Model of Technological Change." Administrative Science Quarterly, December, 35(4), 604- 33.

Ashforth, B. E., Harrison, S.H. and Corley, K.G. (2008), "Identification in Organizations: An Examination of Four Fundamental Questions," Journal of Management, 34, 3, 325-374.

Ashforth, B. E. and Johnson, S.A. (2001), Which hat to wear? The relative salience of multiple identities in organizational contexts, 31-48. In M.A.Hogg and D.J. Terry (Eds), Social Identity processes in organizational contexts. Philadelphia. Psychology Press.

Ashforth, B. E., and Mael, F. (1989) Social Identity Theory and the organization" Academy of Management Review, 14, 20-39.

Birkinshaw, J.M and Hood, N. (1998). 'Multinational subsidiary evolution and charter changes in foreign-owned subsidiary companies'. Academy of Management Review, 23, 4, 773-795.

Boje, D.M (2001) Narrative methods for organizational and communication research, London: Sage Publications. 
Burke, P.J. and Reitzes, D.C. (1991) "An Identity Theory Approach to Commitment”, Social Psychology Quarterly, 54, 3, 239-251.

Bruner, J. (1991) "The narrative construction of reality", Critical Inquiry, 18, 121.

Chandy, R. and Tellis, G. (1998). 'Organizing for radical product innovation: The overlooked role of willingness to cannibalize,' Journal of Marketing Research, 35, November, 474-487.

Chesbrough, H., (2003) "The logic of open innovation: managing intellectual property", California Management Review, 45, 3, 33.

Czarniawska, B. (1997). 'A four times told tale: Combining narrative and scientific knowledge in organisation studies'. Organisation, 4, 7-30.

Department of Enterprise, Trade and Employment, 2008, p. 13

Ettlie, J.E., and Subramaniam, M., (2004), "Changing strategies and tactics for new-product development", Journal of Product Innovation Management, 21, 95-109.

Etzkowitz, H., and Leydesdorff, L., (2000). "The dynamics of innovation: from national systems and 'Mode 2' to a Triple Helix of University-industrygovernment relations", Research Policy, 29, 109-123.

Faems, D., Van Looy, B. and Debackere, K. (2005). 'Interorganizational collaboration and innovation: Toward a portfolio approach'. Journal of Product Innovation Management, 22, 238-250.

Gatignon H. Tushman M.L. Smith W. and Anderson P. (2002), "A Structural Approach to Assessing Innovation: Construct Development of Innovation Locus, Type, and Characteristics", Management Science, 48, 9, pp. 1103-1122.

Gioia, D.A., Schultz, M., and Corley, K.G. (2000), Organizational Identity, Image and Adaptive Instability, Academy of Management Review, 25, 1, 6381.

Gioia, D.A. and Chittipeddi, K. (1991) Sensemaking and sensegiving in strategic change initiation, Strategic Management Journal, 12, 6, 433-438.

Gordon, I.R. and McCann, P. (2000). 'Industrial clusters: Complexes, agglomeration and/or social networks?'. Urban Studies, 37, 3, 513-532.

Gregersen, H.B. and Black, J.S. (1992) Antecedents to commitment to a parent company and a foreign operation, Academy of Management Journal, $35,1,65-90$.

Hannon, E., Monks, K., Conway, E., Kelly, G., Flood, P., Truss, K. and Mastroeni, M. (2011). 'The state and industrial policy in Ireland: a case study of the Irish pharmaceutical sector'. The International Journal of Human Resource Management, 22, 18, 3692-3710. 
Henderson, R., Orsenigo, L., and Pisano, G. (1999). 'The pharmaceutical industry and the revolution in molecular biology: Interactions among scientific, institutional and organizational'. In D.C Mowery and R. R. Nelson (Eds.), Sources of Industrial Leadership: Studies of Seven Industries: 267-311. Cambridge: Cambridge UP.

Jovchelovitch, S. and Bauer, M.W. (2000). Narrative Interviewing, London: LSE Research Online. Accessed 11/04/2012

Lawerence, T., C. Hardy and N. Phillips (2002) "Institutional Effects of Interorganizational Collaboration: The Emergence of Proto-Institutions", Academy of Management Journal, 2, 1, 281-190.

Lee, C., K. Lee and J. Pennings (2001) "Internal Capabilities, External Networks, and Performance: A Study on Technology-Based Ventures", Strategic Management Journal, 22, 615-640.

Leifer, R., McDermott, C.M., O'Connor, G.C., Peters, L., Rice, M., Veryzer, R., (2000) "Radical Innovation: How Mature Companies can Outsmart Upstarts", Harvard Business School Press, Boston.

Lundgren A. (1995) Technological innovation and network evolution, London: Routledge.

Makkonen, H., L. Aarikka-Stenroos and R. Olkkonen (2012) "Narrative Approach in Business Process Research - Implications for Theory and Methodology", Industrial Marketing Management, 41, 287-299.

Markwick, N. and Fill, C. (1997) "Towards a framework for managing corporate identity", European Journal of Marketing, 31, No, 5/6 pp.396-409.

McDermott, C. M. and O'Connor, G. C. (2002) "Managing radical innovation: An overview of emergent strategy issues," Journal of Product Innovation Management, 19, 424-438.

McNally, R. C., Cavusgil, E. and Calantone, R. J. (2010), "Product innovativeness dimensions and their relationships with product advantage, product financial performance, and project protocol," Journal of Product Innovation Management, 27, 7, 991-1006.

Möller, K. (2010), 'Sense-making and agenda construction in emerging business networks - How to direct radical innovation,' Industrial Marketing Management, 39 (3), 361-71.

Mowery, D.C. and Rosenberg, N. (1993), "The US National Innovation System," in National Innovation Systems: A Comparative Analysis, Richard Nelson, ed. New York: Oxford University Press, 29-75.

Orsenigo, L., F. Pammolli and M. Riccaboni (2001) "Technological change and network dynamics: Lessons from the pharmaceutical industry", Research Policy, 30, 485-508. 
Pentland, B. T. (1999). 'Building process theory with narrative: From description to explanation'. Academy of Management Review, 24, 4, 711-724.

Powell, W., Koput, K., and Smith-Doerr, L. (1996) "Interorganizational collaboration and the locus of innovation: The growth of learning in biotechnology", Administrative Science Quarterly, 41, 1, 116-145.

Pratt, M.G. 1998. To be or not to be?: Central questions in organizational identification. In D. A. Whetten and P. C. Godfrey (Eds.), Identity in organizations: Building theory through conversations. Foundations for organizational science: 171-207. Thousand Oaks, CA: Sage.

Pratt, M., (2000) Building an ideological fortress: The role of spirituality, encapsulation and sensemaking, Studies in Cultures, Organizations and Societies, 6, 35-69.

Song M. and Swink M. (2002) "Marketing-Manufacturing Joint Involvement across Stages of New Product Development: Effects on the Success of Radical vs. Incremental Innovations", Academy of Management Proceedings, B1-B6.

Story, V., L. O'Malley and S. Hart (2011) "Roles, Role Performance, and Radical Innovation Competences", Industrial Marketing Management, 40, 6, 952-966.

Stryker, S. and Burke, P.J. (2000) "The Past, Present and Future of an Identity Theory", Social Psychology Quarterly, 63, 4, 284-297.

Tajfel, H. (Ed), (1978) Differentiation between social groups: Studies in the social psychology of intergroup relations. London. Academic Press.

Van Egeraat, C. (2006). 'The Irish pharmaceutical industry over the boom period and beyond'. Irish Geography, 32,

van Riel and Balmer, 1997 "Corporate identity: the concept, its measurement and management", European Journal of Marketing, 31, No, 5/6 pp.340-355.

Vora, D. and Kostova, T. (2007), "A Model of Dual Organizational Identification in the Context of the Multinational Enterprise," Journal of Organizational Behavior, 28 (3), 327-350.

Wengraf, T. (2001). Qualitative Research Interviewing: Biographic Narrative and Semi Structured Methods. London: Sage. 
TABLES

Table 1: Informants

\begin{tabular}{|c|c|c|}
\hline Informant & Organisation & Experience Context \\
\hline 1/Philip & University 1 & Industry and Academic \\
\hline 2/Donald & University 1 & Industry and Academic \\
\hline 3 & University 1 & Industry and Academic \\
\hline 4 & University 2 & Industry and Academic \\
\hline 5/Kevin & University 3 & Industry and Academic \\
\hline 6 & University 4 & Industry and Academic \\
\hline 7 & University 5 & Industry and Academic \\
\hline 8/William & Pharmaceutical Company 1 & Industry and Academic \\
\hline 9/Peter & Pharmaceutical Company 2 & Industry and Academic \\
\hline 10/Geoff & Pharmaceutical Company 3 & Industry and Academic \\
\hline 11 & Pharmaceutical Company 4 & Industry \\
\hline 12 & Pharmaceutical Company 5 & Industry \\
\hline 13 & Pharmaceutical Company 6 & Industry and Academic \\
\hline 14 & Pharmaceutical Company 7 & Industry and Academic \\
\hline 15 & Pharmaceutical Company 8 & Industry \\
\hline 16 & Pharmaceutical Company 9 & Industry \\
\hline 17 & Pharmaceutical Company 10 & Industry \\
\hline 18 & Pharmaceutical Company 11 & Industry and Academic \\
\hline
\end{tabular}

